\title{
收: 1949 INTERNATIONAL GEOGRAPHICAL CONGRESS
}

$\mathrm{T}$ HE International Geographiced fongress, postponed from September la w, was held at Lisbon during April 8-15 (holy the presidency of Prof. Emm. de Martonn hirty-four countries were represented, adc suing to the list of members, among the sevel hurared delog thes and adherents. There we trong delegations from Brazil, the United States, Fupec, Belgium Switzerland, Italy, Spain and the Scandhavian countries, but the U.S.S.R. was not represented. Between thirty and forty attended from Great Britain-a widely representative group. The seven sections and the various commissions held their meetings in the palatial Higher Technical Institute, a new building in a commanding position in the modern north-eastern sector of Lisbon. Numerous social occasions, including a gala performance at the São Carlos Theatre, which the Portuguese organised superbly well and with most lavish hospitality, gave abundant opportunities for those international contacts which are perhaps the most valuable and lasting features of such congresses. The importance attached by the Portuguese hosts to the occasion was marked by the presence of the President himself at the opening ceremony held in the National Parliament Building.

Practically the whole of the work of the Congress was carried on in either French or English, and the discussions in the sectional meetings-usually well attended-proceeded with the utmost cordiality. Running through the whole work of the Congress was the realization, so marked in recent years, that geographical analysis and methods of survey have an important part to play in the solution of the great world problems of the day, that such an approach is an essential complement to economic and social analysis and can be carried on apart from political considerations. The whole atmosphere at Lisbon was scientific and non-political. Evidence of this modern development was afforded by the fifty or more papers read to the section of human geography on different aspects of rural life, modern developments of transhumance in relation to soil erosion, and in the whole section devoted to colonial problems, as well as in the appointment of commissions (the work of which continues between Congresses) to deal with physical planning, agricultural geography and the possibility of a world inventory in map form of land use and land resources. Practical issues were also to the forefront in the work of the commission on aerial photography and the study of industrial ports.

The actual Congress was preceded by an excursion, largely attended by the American delegation, and was followed by four alternative excursions to different parts of Portugal and one to Madeira. The guide-books prepared for the excursions, as well as the actual leadership, supplied excellent evidence of the high level reached by academic geographers in Portugal.

A feature of the Congress was the exhibition of cartography, which included notable displays of modern maps from many countries, ranging from the Vatican State to the United States. Whether through lack of appreciation of the occasion or parsimony of the Treasury, it is a tragedy that Great Britain was not officially represented at this exhibition, though few maps attracted more attention or com. ment than the National Planning Series (1:625,000) displayed in the cartography section to illustrate one of the papers.

At the closing session the invitation of the United States was accepted for the next Congress to be held in 1952. Prof. de Martonne was elected honorary life president of the International Geographical Union, while Prof. G. B. Cressey (Syracuse University, United States) becomes president, with Mlle. Lefèvre (Belgium), Prof. Almagia (Italy), Prof. Orlando Ribeiro (Portugal-the organiser of the Lisbon Congress), Prof. Hans Boesch (Switzerland), Prof. L. Dudley Stamp (Great Britain), Prof. Leite de Castro (Brazil) and Prof. George Kuriyan (India) as the vice-presidents who constitute the executive committee. With the election of Prof. G. H. T. Kimble (McGill University, Canada) as secretarygeneral the secretariat will move from Brussels to Montreal.

The International Union normally contacts the National Geographical Committee in each adhering country, and the conference proceedings brought out the difficulties which may result where such a national committee is divorced from the main geographical societies. The position in Great Britain is particularly anomalous. Geographers have not yet been recog. nized, as such, by election to the Royal Society, yet the National Committee is a committee of the Royal Society and the chairman must be a Fellow of the Society. As a result, the British delegation seemed to lack the coherence so markedly displayed by the American.

L. DUdLey Stamp

\section{A MOUNTAIN CENTRE OF GENETICS IN THE APPENNINES}

\author{
By Prof. CARLO JUCCI \\ “L. Spallanzani" Institute of Zoology, University of Pavia
}

$T$ HE genetical chtre of the Italian National Council of Regarch, which is associated with the "L. Spallanzani. Institute of Zoology of the University of Pavig, is organising a Mountain Section in the Appennines on Mount Terminillo, at a height of 1,800 n. This Mountain Centre of Genetics is designod for the investigation of those plants and animals which are particularly suited for the study of processes of racial and specific differentiation; that is, of micro-evolution, according to the principles and methods of modern population genetics.

The mountain environment, with its characteristic complex of geographical, climatic and ecological conditions, imposes peculiar adaptations on animals and plants, and the genetical basis of these adaptations is particularly significant when it is studied in com. parison with corresponding systematic entities in. habiting the plains or different altitude levels. The exploration of the amplitude of phenotype variations consequent on 'transfer' from one habitat to another (and this applies also to culture in nutrient solutions) and the exploration of the potentialities of genotype variation by induction of mutations with X-irradiation should extend the comparative analysis and furnish data for an interpretation of evolutionary mechanisms and modes. 